\title{
Programa de Visita Humanizada em Uti
}

\author{
Caldeira, Lucilene Martins; Migotto, André Esteves; Fonseca, Thabata Larissa Campos; \\ Rodriguez, Lórgio Henrique Diaz \\ Icesp - Instituto do Cancer do Estado de São Paulo - lucilene.caldeira@icesp.org.br
}

INTRODUÇÃO As reações de familiares à internação de parentes em UTI são geralmente interdependentes às características do processo de adoecimento. de fato, a estadia de um paciente na UTI é uma condição de estresse absoluto para os familiares. Esta condição é vivenciada como uma crise real pela família. Isto se deve às condições de incerteza e insegurança que vive durante o processo de internação do paciente, diante de prognósticos difíceis e complexos, que caracterizam as situações da maior gravidade. Os principais estressores aos familiares são: impacto emocional da necessidade de transferência para UTI, privação do papel de cuidador, comportamento do paciente e suas reações, mudança na aparência de seu ente querido e aparelhos invasivos; sons e ruídos do ambiente; procedimentos de emergência com pacientes no momento da visita; dificuldade de comunicação da equipe com a família; a compreensão simplificada do quadro clínico do paciente, dificuldade de entendimento do motivo da internação na unidade e condutas terapêuticas, muitas vezes invasivas. OBJETIVO Acolher e proporcionar aos familiares atendimento humanizado e diferenciado em situação de crise. Diminuindo assim, situações que possam favorecer descompensação emocional. MATERIAL e MÉTODOS: a Visita Humanizada na UTI ocorre desde Março de 2009, diariamente nos horários de visita (10:00 às 11:00/16:00 às 17:00/20:00 às 21:00), além de exceções em que as visitas são estendidas, de acordo com avaliação da equipe multiprofissional. nos horários que antecedem as visitas, os psicólogos de referência (três), recebem os familiares na sala de espera da UTI, realizam acolhimento, avaliação psicológica e intervenção breve, de apoio e orientação, e preparo psicológico para a visita. Quando necessário, acompanha-se o visitante beira-leito. ao final do horário de visitas, realiza-se atendimento, com o objetivo de compreender a percepção do familiar sobre o momento atual e impacto emocional reativo ao momento vivenciado. Finalizando com evolução em prontuário eletrônico, documentando o atendimento. RESULTADOS: Desde sua criação em Março de 2009 até Dezembro de 2013, foram realizados atendimento e acompanhamentos a 13.127 familiares durante o Programa de Visita Humanizada. CONCLUSÃO com o Programa Visita Humanizada em UTI observamos e vivenciamos: efetividade na comunicação, qualidade na relação médico-familia-equipe, proporcionar assistência integral, biopsicossociocultural e espiritual aos usuários, como preconiza a OMS. Desta forma, é possível minimizar os quadros de descompensação psicológica, estimular comportamentos resilientes e fortalecer recursos internos de enfrentamento e comportamentos adaptativos dos cuidadores; oferecer suporte emocional e orientação aos familiares para lidar com os fatores inerentes à situação de crise e internação na unidade, e favorecer prática humanizada e interprofissional em saúde, com atendimento humanizado e de excelência a todos os envolvidos.

\footnotetext{
Caldeira, Lucilene Martins; Migotto, André Esteves; Fonseca, Thabata Larissa Campos; Rodriguez, Lórgio Henrique Diaz. Programa de Visita Humanizada em Uti. In: Anais do Congresso Internacional de Humanidades \& Humanização em Saúde [= Blucher Medical Proceedings, num.2, vol.1]. São Paulo: Editora Blucher, 2014. ISSN 2357-7282

DOI 10.5151/medpro-cihhs-10727
} 